\title{
Lo malo de la nicotina
}

\section{Nicotine effects}

\author{
Aranza P. Gutiérrez Cruz ${ }^{1}$ *, Yulisa Hernández Jiménez², Leobardo Falcón Valdez³, Eduardo \\ D. Mendoza Altamira ${ }^{4}$
}

\begin{abstract}
:
In Tobacco there are around 4000 toxic substances, however nicotine is one of the main components that cause addiction in the consumption of this, said substance is an organic compound of the alkaloid type; which is extracted from the tobacco leaves and sold in the world market between 1 and 2 milligrams per cigarette. Highlighting the most important in reference to our interest; is to understand the peculiar addictive properties of this substance, as well as the mechanisms and adverse effects that are developed in the organism when consuming this substance mainly in the central nervous system and some other organs involved, in addition to analyzing the social vulnerability that exists for the consumption of this drug.
\end{abstract}

Keywords:

Tobacco, nicotine, addiction, central nervous system, toxic, vulnerability, nicotinic receptors.

\section{Resumen:}

En el Tabaco hay alrededor de 4000 sustancias toxicas, sin embargo, la nicotina es uno de los principales componentes que causan la adicción en el consumo de este, dicha sustancia es un compuesto orgánico del tipo alcaloide; el cual se extrae de las hojas del Tabaco y se comercializa en el Mercado mundial entre 1 y 2 miligramos por cigarrillo. Destacando lo más importante en referencia a nuestro interés; es comprender las peculiares propiedades adictivas de esta sustancia, así como los mecanismos y efectos adversos que se desarrollan en el organismo al consumir esta sustancia principalmente en el sistema nervioso central y algunos otros órganos involucrados, Además de analizar la vulnerabilidad social que hay por el consumo de esta droga.

\section{Palabras Clave:}

Tabaco, nicotina, adicción, Sistema nervioso central, toxica, vulnerabilidad, receptores nicotínicos.

\section{Desarrollo}

La principal razón del porque la sociedad consume el tabaco, se debe a que este producto contiene una poderosa droga llamada nicotina.

\subsection{Definición de la nicotina}

La nicotina se puede definir como un alcaloide líquido, oleaginoso, incoloro y toxico presente en el tabaco. Este compuesto se disuelve muy fácilmente en agua y alcohol. En la actualidad se han encontrado alrededor de 4000 sustancias toxicas presentes en el tabaco, entre las cuales la nicotina es la sustancia que produce la adicción y la dependencia, además de que es la sustancia más abundante. Podemos denotar que una dosis toxica en los humanos sería de entre 10 y 20 mg de nicotina, haciendo énfasis en que si esta se administra vía intravenosa seria letal para el ser humano.

\section{$1.2 \quad$ Historia de la nicotina}

La planta de tabaco se conoce desde hace aproximadamente 10000 años, esta panta ancestralmente se utilizaba para rituales religiosos. (Los norteamericanos usaban la palta del tabaco como parte de un ritual al fumar la pipa de la paz como un lazo de amistad)

Fue considerada como un regalo de bienvenida por parte de los americanos para los europeos, se cree que Cristóbal Colón fue el primero en llevar plantas de tabaco al viejo continente, donde la aristocracia la utilizaba como plantas de ornato.

${ }^{1}$ Lic. Médico Cirujano, Universidad Autónoma de Estado de Hidalgo, Escuela superior de Tepeji del Rio, Av. Del Maestro No. 41 Colonia Noxtongo $2^{\text {a }}$ Sección, Tepeji del Rio, Hidalgo, México. Email: aranza992011@hotmail.com, 2 hyuli778@gmail.com, 3 leo01516@gmail.com, 4daniimendoza24@gmail.com. 
Gracias a la economía en el año de 1573 presentaron la planta de tabaco ante la corte de la reina Elizabeth I y en menos de 40 años ya se comercializaba por miles de tiendas que lo vendían para un uso recreativo.

Esta sustancia fue llevada a Asia y África por los portugueses y españoles y para el siglo XVI sus productos derivados habían sido distribuidos por todo el mundo. (http://www.uaslp.mx/Comunicacion-

Social/Documents/Divulgacion/Revista/Catorce/220/05.p df, la nicotina de la adicción al uso médico.) [1]

Las semillas de tabaco se hicieron populares en los clubes de fumadores en Inglaterra, y en Francia inhalar el humo de la planta representaba cerca del $90 \%$ de las formas de consumo.

Sus propiedades medicinales son ancestrales y tiene, además, múltiples usos, los aztecas mezclaban la hoja con cal, abrían los tumores en forma de cruz y colocaban la mezcla, en ocasiones lo usaban como antídoto del veneno de serpiente, las mujeres embarazadas ponían en su seno hojas de tabaco para librar a sus hijos de enfermedades.

"En el sur del continente americano se llagaban a utilizar las hojas para cicatrizar las heridas, costumbre que fue adoptada por los europeos". (http://www.uas/p.mx/Comunicacion-

Social/Documents/Divulgacion/Revista/Catorce/220/05.p df, tabaco un regalo de la naturaleza.) [2]

\subsection{Mecanismo de acción}

La nicotina tiene efectos sobre las áreas que forman parte del sistema de "recompensa" en el SNC. como lo son en el segmento ventral del mesencéfalo y el nucleus accubens del prosencéfalo.

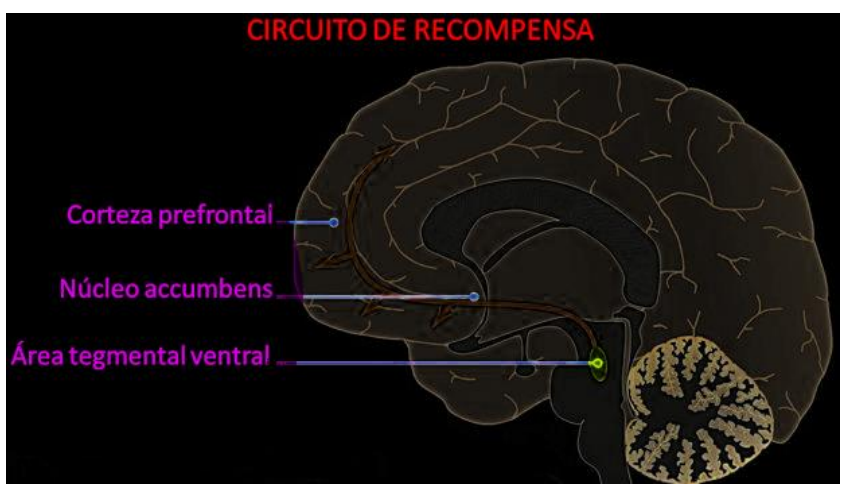

Figura 1. Áreas del sistema de recompensa

La nicotina se vincula en esta área a los receptores nicotínicos de la acetilcolina (nAChR) de las neuronas, actúa en estos receptores, ya que la estructura de la nicotina tiene un parecido al de la acetilcolina.
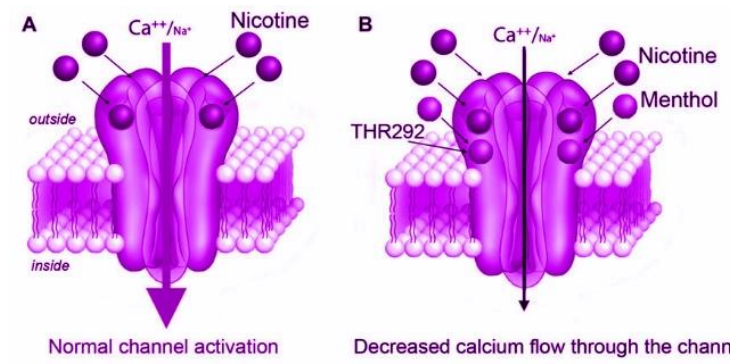

Figura 2. Receptores nicotínicos

Depende del lugar en donde actúen y de sus efectos celulares tanto funcionales, los receptores pueden ser de tipo muscular o de tipo neuronal. La acetilcolina actuara como agonista endógeno en ambos tipos de receptores y la nicotina actuaria solamente como agonista exógeno en los receptores neuronales. (Morales, (2017), págs. 22-27) [4]

Esta sustancia se adhiere e imita al neurotransmisor acetilcolina, que se acopla a las proteínas caniculares y así cuida que las neuronas liberen suficiente dopamina.

El efecto de la nicotina en las neuronas dura unos cuantos minutos, lo cual promueve la excitación de estas neuronas involucradas y el efecto se ira debilitando poco a poco.

En las neuronas gabaérgicas se acoplará la nicotina, estas neuronas se encargan de liberar el neurotransmisor ácido gamma aminobutírico (GABA), que va a controlar la liberación de dopamina hacia las neuronas vecinas, si estas son sobre-nicotinizadas, la secreción del neurotransmisor se verá limitado, por lo cual la excitación de dopamina hacia otras neuronas aumentará. (María, (2015)) [3]

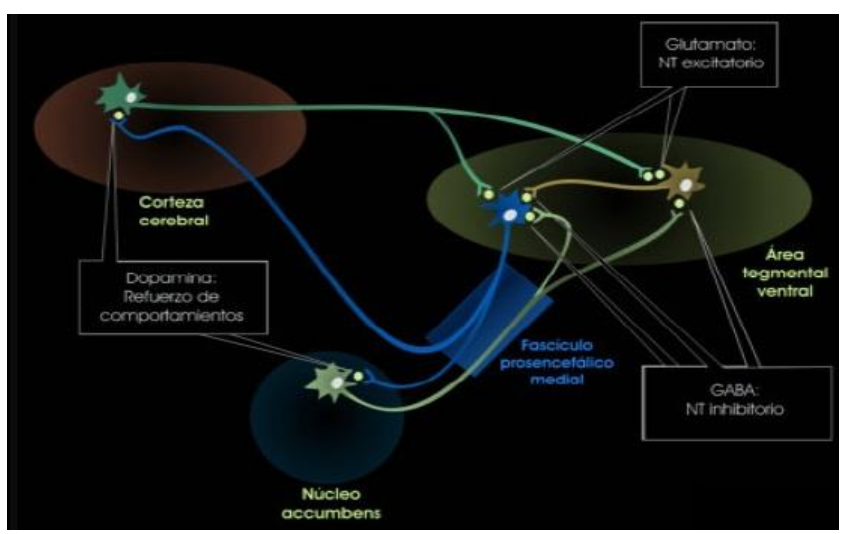

Imagen 3. Neuronas gabaérgicas

Esto se da a consecuencia de que las células adaptaran su forma bioquímica y va a ser en dos fases:

1. Crecerán los receptores de nicotina

2. Aumentará la secreción de dopamina

Esto provocara que las neuronas con el tiempo tendrán una reacción menos inmediata, pues necesitaran aumentar la cantidad para consumir. 


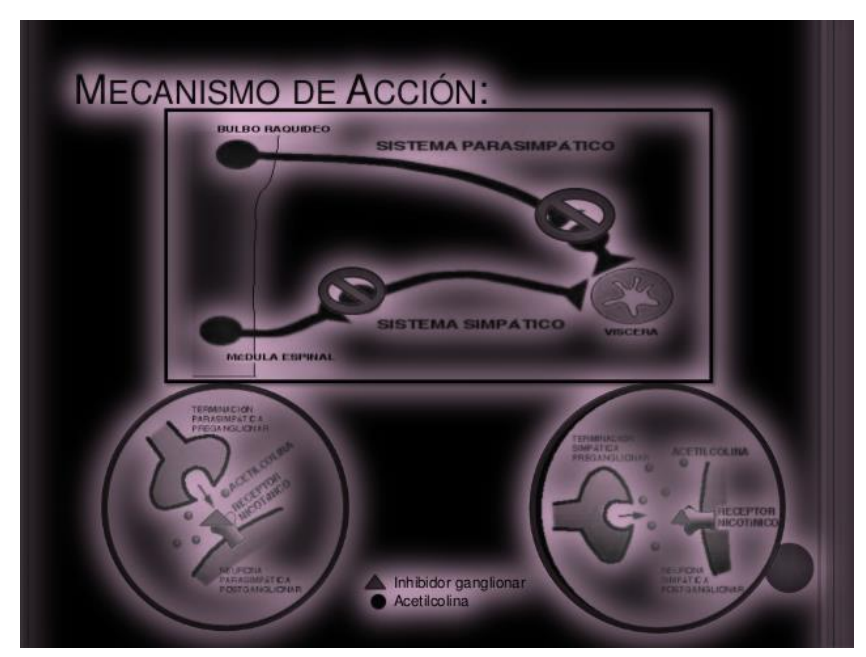

Imagen 4. Mecanismo de acción de la nicotina

\subsection{Efecto de la nicotina en el cerebro}

La inhalación del humo del Tabaco es la manera más fácil y eficiente de administrar nicotina al organismo, porque la pasa del pulmón directamente al ventrículo izquierdo y de ahí directamente al cerebro y las neuronas.

A partir de ahí, la nicotina llega rápidamente al cerebro y atraviesa la barrera entre sangre y cerebro donde comienza a cambiar el funcionamiento del cerebro durante este proceso tan solo trascurren sólo 10 segundos, tiempo menor al de una inyección intravenosa, así que Cuando esta ingresa al organismo activa a algunas estructuras normales del cerebro, conocidas como receptores. Cuando los receptores se activan, liberan una sustancia química llamada dopamina en el núcleo accumbens, que provoca una sensación de bienestar por lo cual causa la dependencia esta sustancia.

La nicotina también activa el locus cerúleos, lo cual causa una liberación de norepinefrina que lleva a una activación generalizado del cerebro; aumento de la concentración, mejora la capacidad de memoria y habilidad intelectual, así como el aumento de la habilidad para resolver problemas. Además, la norepinefrina disminuye el apetito, lo que ocasiona que los fumadores tengan menor peso que los no fumadores.

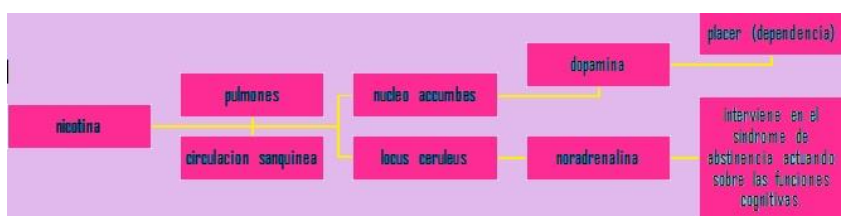

Imagen 5. Mapa sobre la reacción en el cerebro

\section{Conclusiones}

La nicotina como principal componente del cigarro, se caracteriza por ser una sustancia química que a nivel cerebral provoca la liberación de dopamina, esta desencadena una sensación de bienestar que además provoca una situación de dependencia y a través de eso la persona necesita cada vez dosis superiores para desencadenar las reacciones, como consecuencia de esto y de estar acompañada de otras 4,000 sustancias nocivas para el organismo son las responsables de los efectos malos del tabaco. "La nicotina por sí sola no es perjudicial sino hasta que se combina con el resto de los componentes"

\section{Agradecimientos}

Queremos agradecer al doctor Tangirala Venkata Krishna Karthik, por haber revisado de forma crítica nuestro artículo, así como hacernos observaciones para mejorar nuestra investigación. Al igual agradecer a todos nuestros compañeros por haber revisado y hecho críticas en cuanto a mejora de redacción en nuestro trabajo.

\section{Bibliografía}

[1] http://www.uas/p.mx/Comunicacion-

Social/Documents/Divulgacion/Revista/Catorce/220/05.pdf, la nicotina de la adicción al uso médico.

[2] http://www.uas/p.mx/Comunicacion-

Social/Documents/Divulgacion/Revista/Catorce/220/05.pdf, tabaco un regalo de la naturaleza.

[3] María, A., \& Roldán, T. (2015). Atención y Nicotina.

[4] Morales, M. M., Atzori, M., \& Ciencias, F. D. E. (2017). La nicotina, 22-27.

Haga clic o pulse aquí para escribir texto. 